\title{
PROCESSO DE ORIENTAÇÃO PARA AMAMENTAR: A DESARTICULAÇÃO DA EDUCAÇÃ̃O REALIZADA À BEIRA DO LEITO
}

\author{
BREASTFEEDING ORIENTATION PROCESS: THE DISARTICULATION OF EDUCATION PROVIDED \\ $B E D S I D E$
}

\author{
Juliana da Silva Garcia Nascimento a , Fabiana Cristina Pires ${ }^{b}$, Larissa Andrade Pereirac, \\ Fernanda Cristina Moraes Borges ${ }^{\mathrm{d}}$, Thais Cristianne dos Santos Silva ${ }^{\mathrm{e}}$ \\ amestradounesp28@yahoo.com.br, benfermagem.pires@gmail.com, clala_andrade@hotmail.com, dfer.cmborges@hotmail.com, \\ ethayscristianne6@gmail.com \\ Universidade de Uberaba - Uberaba (MG), Brasil
}

Data de recebimento do artigo: 12/06/2017

Data de aceite do artigo: 03/08/2017

\section{RESUMO}

Introduçáo: O leite materno é o primeiro alimento da criança e, portanto, é imprescindível a orientaçấo educacional à beira-leito nesse âmbito. Objetivo: Compreender o processo de orientaçáo necessário para amamentaçấo da perspectiva dos enfermeiros e das mães. Métodos: Estudo descritivo exploratório, com abordagem qualitativa, realizado por meio de entrevista semiestruturada gravada com quinze puérperas e quatro enfermeiros. Resultados: A percepção dos enfermeiros possibilitou identificar dois temas: o primeiro se refere às orientaçóes realizadas para amamentar, a saber: o tempo em que o bebê deve permanecer mamando; a pega correta; o posicionamento correto; a necessidade de alternar a mama; o intervalo da mamada. As dificuldades envoltas nesse processo foram o segundo tema, configurando a falta de conhecimento e a insegurança da puérpera para amamentar; a necessidade de o enfermeiro apropriar-se da sua funçáo de educador; a demanda de fortalecer o vínculo entre atenção primária e atençâo terciária na saúde. A análise da percepção das puérperas também gerou dois temas: orientaçôes recebidas beira-leito cujas referências corroboraram as realizadas pelos enfermeiros; contradiçóes nas abordagens educacionais, evidenciando as diferentes formas de realizar as orientaçôes pelos profissionais. Conclusóes: Apesar de o processo de orientaçâo realizado pelos enfermeiros configurar as mesmas instruçóes percebidas pelas puérperas, identificaramse lacunas na educação realizada beira-leito quanto ao alinhamento da fala profissional, evidenciando a desarticulação do processo e dificultando a compreensão da puérpera, o que reforça ser necessária a adoção de protocolos.

Palavras-chave: Aleitamento materno; educaçáo; período pós-parto.

\section{ABSTRACT}

Introduction: Breastmilk is the child's first food, which makes educational guidance at bedside essential in this context. Objective: To understand the orientation process needed to breastfeed from the perspective of nurses and mothers. Methods: A descriptive, exploratory study with a qualitative approach, performed through a semi-structured interview with fifteen puerperal women and four nurses. Results: The nurses' perception made it possible to identify two themes: the first is related to the guidelines for breastfeeding, namely; the time the baby should remain nursing; the correct handle; the correct positioning; need to alternate breast; the feeding interval. The difficulties involved in this process were the second theme setting; the lack of knowledge and the insecurity of the puerperal woman to breastfeed; the need for nurses to take ownership of their role as educators; the need to strengthen the link between primary care and tertiary care in health. The analysis of the puerperal woman perception also generated two themes: received references to bedside, whose references corroborated those made by the nurses; contradictions in the educational approaches, showing the different ways of carrying out the orientations by the professionals. Conclusions: Despite the orientation process carried out by 
the nurses, the orientation perceived by the puerperal women have identified gaps in the education carried out on the bedside as to the alignment of professional speech, evidencing the disarticulation of this process and making it difficult for the puerperian to understand, which reinforces the need for adoption of protocols.

Keywords: Breast feeding; education; postpartum period.

\section{Introdução}

O leite materno é o primeiro alimento da criança e a protege substancialmente no início da vida ${ }^{1}$. Em meados do século 20 , foram criadas políticas e programas de incentivo no Brasil voltados à amamentação, dando ênfase à prática exclusiva ${ }^{2}$. Atualmente, a Organização Mundial da Saúde, o Fundo das Naçóes Unidas para a Infância e o Ministério da Saúde recomendam que a amamentação seja a única forma de alimentação do bebê até os primeiros 6 meses de vida, podendo ser complementada até os 2 anos de idade 3 .

No Brasil, apenas $41 \%$ das máes amamentam exclusivamente até os 6 meses, e esta taxa ainda representa o dobro da registrada nos Estados Unidos, no Reino Unido e na China ${ }^{4}$. Mesmo assim, o Brasil é apenas o $21^{\circ}$ país com a maior duraçáo de amamentação exclusiva, o que demonstra a necessidade de aperfeiçoamento na adesão a esta prática ${ }^{4}$.

Diante desta perspectiva, acredita-se que o conhecimento sobre o processo para amamentar, pautado em orientaçóes protocoladas e de qualidade, realizado pelos profissionais de saúde é fundamental para o binômio mãe e filho na busca da valorização de seus benefícios nutricionais, emocionais, imunológicos, econômicos, sociais e de desenvolvimento 5 .

$\mathrm{O}$ entendimento das mulheres sobre amamentação influencia diretamente na atitude destas frente ao ato de amamentar e, nesse contexto, vale a pena ressaltar que, apesar de culturalmente haver a filosofia de que as orientaçóes pertinentes à amamentação devem ser realizadas no período de pré-natal, a assistência hospitalar, principalmente após o nascimento, requer atenção quanto aos processos de orientação das mães frente aos desafios ao amamentar ${ }^{6}$.

O puerpério imediato é uma fase de mudanças hormonais e emocionais da vida da mulher, e é nesse período que o enfermeiro precisa estar atento às possíveis complicaçóes, demonstrar apoio emocional e orientar sobre essa fase de grandes transformaçóes ${ }^{7}$.

A interrupçáo precoce da amamentação tem sido relacionada ao desconhecimento materno sobre a maneira adequada para amamentar e ao despreparo dos profissionais de saúde ao orientar as mulheres, portanto o conhecimento é um fator determinante para o sucesso desta prática e, nesse sentido, acredita-se que investigar o conhecimento das mães sobre aleitamento materno pode contribuir para o direcionamento das açóes educativas e para a reorientação das instruçóes adotadas pelos profissionais enfermeiros ${ }^{8}$.

A falta de alinhamento na comunicação e de capacitação profissional para a promoção

do aleitamento materno pode ser uma das causas do desmame precoce, pois se o profissional náo compreende as práticas ou se a equipe de enfermeiros encontra-se desarticulada frente às orientaçóes necessárias para amamentar, não é possível transmitir as orientaçôes e atribuiçóes para as puérperas com a segurança e qualidade que este processo requer?.

Diante desse cenário, a orientação educacional realizada à beira-leito pelo enfermeiro sobre amamentação torna-se imprescindível, já que este profissional atua na gestáo do cuidado e propicia qualidade na assistência prestada $^{10}$.

Compreendendo que o enfermeiro é o profissional que detém a mais estreita relaçáo com a mulher durante o ciclo gravídico puerperal e tem fundamental papel nos programas de educação em saúde, há expectativa de que este prepare a puérpera para o momento da amamentação, adaptando-a da melhor maneira ${ }^{10}$.

Refletindo sobre este contexto, foi delimitada a seguinte pergunta norteadora: como se caracteriza o processo de orientação para a prática da amamentação na perspectiva de enfermeiros e puérperas em ambiente hospitalar? Há divergências entre as orientaçóes realizadas pelos profissionais e as percebidas pelas puérperas? Esta pesquisa teve como objetivo compreender o processo de orientação para amamentação do ponto de vista dos enfermeiros e das puérperas, verificando as lacunas existentes e as possíveis contradiçóes entre o que é ensinado e o que é praticado.

\section{Métodos}

Trata-se de um estudo descritivo exploratório, com abordagem qualitativa, realizado em uma maternidade de um hospital universitário do interior do estado de Minas Gerais que possui 30 leitos. A coleta de dados foi realizada no período de outubro a dezembro de 2016.

A população do estudo foi composta por quatro enfermeiros assistenciais e quinze puérperas. Os critérios 
de inclusão adotados para o profissional enfermeiro foram: exercer a função assistencial no setor de maternidade, pertencer à escala de trabalho e admitir puérperas realizando as orientaçóes para amamentação. Foram excluídos enfermeiros que não faziam parte da escala assistencial, que estavam afastados do trabalho por licença médica ou outras licenças ou que estavam de férias. Quanto às puérperas participantes, foram incluídas as maiores de 18 anos, que já tinham iniciado a primeira amamentação no setor e referiram ter sido orientadas pelo profissional enfermeiro do setor de maternidade sobre amamentaçáo. O número de participantes foi delimitado pelo critério de saturaçáo dos dados ${ }^{11}$.

O manual Saúde da Criança: Aleitamento Materno e Alimentação Complementar - 2015 embasou este estudo como referencial teórico ${ }^{11}$.

Os dados relacionados às concepções e às experiências do enfermeiro e das puérperas sobre o processo de amamentação foram coletados por meio de entrevista semiestruturada gravada, seguindo roteiro previamente estipulado, com seis questóes norteadoras elaboradas pelas pesquisadoras. Foi realizado um teste piloto para adequação das indagaçóes com cinco puérperas e duas enfermeiras, proporcionando reestruturação do instrumento e fidedignidade na busca dos objetivos.

As entrevistas foram agendadas previamente pela entrevistadora, tomando os devidos cuidados para que não houvesse interferências no andamento institucional. A análise do material obtido se deu por temas, de acordo com a metodologia de análise de conteúdo ${ }^{12}$. As orientações para amamentação realizadas pelo profissional enfermeiro foram descritas, identificando o profissional com a letra E. A análise destes achados identificou dois temas principais: as orientaçôes para amamentação realizadas e a percepção dos profissionais quanto à necessidade de aperfeiçoamento deste processo. Quanto as puérperas, foi analisado um tema que abordou a percepção das mães quanto ao processo de orientação recebido. Elas foram identificadas em suas falas com a letra P.

$\mathrm{O}$ estudo respeitou as exigências formais contidas nas normas nacionais e internacionais regulamentadoras de pesquisas envolvendo seres humanos, recebendo o número 1.841.838 de aprovação.

\section{Resultados}

Duas populações foram entrevistadas: o profissional enfermeiro e as puérperas. Em relaçáo ao sexo dos enfermeiros, todas as quatro participantes eram mulheres. A idade variou de 24 a 54 anos. O tempo de formação na enfermagem revelou profissionais com 1 ano a 8 anos de formação. $\mathrm{O}$ menor tempo de assistência destinado à área materno-infantil na instituição foi de 2 anos e 6 meses e o mais longo de 3 anos e 8 meses. Apenas uma participante não possuía especialização na área materno-infantil.

Foram entrevistas quinze puérperas. A idade delas variou de 18 a 34 anos. A puérpera com maior número de filhos teve quatro gestaçóes. Duas puérperas indicaram ser solteiras e todas as outras, casadas. O menor grau de escolarização identificado foi o ensino fundamental incompleto, representando a maioria das participantes.

Quanto aos achados sobre o processo de orientação para amamentar, foram destacadas quatro categorias: as orientaçôes realizadas pelos enfermeiros para promoção do processo de amamentação; as lacunas no processo de orientaçáo para amamentar percebidas pelo enfermeiro; as orientações recebidas beira-leito; as percepções das puérperas e as contradiçóes nas abordagens educacionais realizadas pelos enfermeiros. Estes resultados foram descritos a seguir.

\section{Orientações realizadas pelo profissional en- fermeiro para promoção do amamentar}

Foram identificadas cinco principais orientaçóes destacadas pelos profissionais. A primeira abordou o tempo que o bebê deve permanecer mamando:

Eu oriento a deixar aproximadamente de 20 a 30 minutos em cada mama. (E1)

Cada mamada tem que ser de no minimo 20, 30 minutos contados no relógio, é isso que eu oriento para as puérperas internadas aqui. (E3)

A segunda orientação tratou do ensino da pega correta para a amamentação:

Eu ensino a pega correta, o posicionamento correto da mama, abocanhando sempre o máximo da aréola possível, não só no bico, porque pode ferir. (E2)

Observa a pega, na hora que pôr no peito, se a boca está com os lábios voltados para fora, cobrindo quase toda a aréola. (E3)

Observar o recém-nascido conforme a pega, se ela achar que não está adequada, chamar a gente. Você orienta e mostra a mãe que faz tipo um " $C$ " na mama, vê se está realmente na boca do neném. (E4)

A terceira indicação do profissional destacou o posicionamento correto para o momento da amamentação:

Deve ficar barriguinh a com barriguinha, ficar em uma posiçâo mais confortável para a máezinha. (E1) 
No posicionamento adequado eu explico que sempre deve estar colocando barriga com a barriga da mäe, a cabecinha no rumo do cotovelo. (E2)

A quarta orientação versou sobre a necessidade de alternar a mama a cada mamada:

A mãe deve intercalar as mamadas, por exemplo, às $6 \mathrm{~h}$ na mama direita, às $9 h$ na mama esquerda. (E1) Alternar sempre as mamas, vai pôr de um lado depois de 3 horas ou conforme necessidade vai colocar no outro. (E2) Cada mamada tem que ser em uma mama só, você só vai trocar de mama na outra mamada. (E3)

A quinta orientação indicou a preocupação com o intervalo entre uma mamada e outra:

Coloca de um lado depois, e depois de 3 horas ou conforme necessidade vai colocar do outro. (E2)

Quando eu vejo que a produção está bem pouca, eu oriento pôr a cada 2 horas e não esperar as 3 horas. (E3)

O periodo de intervalo é a cada 3 horas. (E4)

\section{Lacunas no processo de orientação para amamentar percebidas pelo enfermeiro}

A primeira necessidade percebida correspondeu à falta de conhecimento e à insegurança da puérpera que devia amamentar:

A mãe acha que não tem produção de leite e ela tem o colostro, mas ela náo acredita que a produção esteja sustentando o filho. Eu acho que essa é uma das principais dificuldades das mães. (E2)

A noite principalmente elas têm dificuldade enorme de acordar, o acompanhante não ajuda, o acompanhante da maternidade é despreparado, então, eu sei que tem os cursos, mas assim se tivesse mais curso para preparar $o$ acompanhante, que os cursos vão a mãe e o pai e quem vai acompanhar é a tia, a vó que náo fez o curso. Entâo assim cuidados com o umbigo, cuidados para arrotar, elas não colocam para arrotar. Ab! Sabe, na amamentação, elas não sabem de amamentação, póe de cá, póe de cá, põe de cá, póe de cá, deixa 5 minutos, ele está mamando? (E3)

O segundo apontamento salientado pelos enfermeiros foi a necessidade de se apropriar de sua funçâo de educador:

Então às vezes os técnicos não orientam, que isso é função deles também, e não fica só com a gente e ai aquela que não foi orientada durante o dia você passa na visita você tem que orientar de novo, e às vezes você orienta e elas não entendem, e fala que não foi orientada. (E3)

O terceiro apontamento citado pelos enfermeiros foi a necessidade de fortalecer o vínculo entre atenção primária e atenção terciária na saúde:

Eu acho que deveria melhorar, eu acho que orientação tinha que começar lá no pré-natal, alguém falar para ela, o amamentar não é fácil, amamentar não é igual na novela. Sabe preparar a mama, as que tem o mamilo invertido já vir com o intermediário para cá, quem tem mamilo plano já vem para cá com o intermediário, tinha que vir orientado e não vem. (E3)

Ela não foi orientada, o acompanhante não foi orientado que o menino chora, que o menino mama a cada 3 horas, elas não têm essa orientação direito. Então eu acho que, se orientasse no pré-natal direitinho, ela não assustaria tanto depois no pós-parto, no puerpério. A sua vida vira do avesso, ele só quer o seu peito, e o seu peito está machucado. Elas tinham que receber essa orientaçâo antes de ganhar neném. (E4)

\section{Orientações recebidas beira-leito: percep- ções das puérperas}

A primeira orientação destacada por elas foi quanto ao intervalo entre cada mamada:

Ela falou para mim que diz que... ele tinha que mamar a cada 3 horas. (P1)

O intervalo... a cada 2 horas porque ela é recém-nascida e eu estou usando só o leite materno, a cada 2 horas. (P3)

A segunda orientação foi sobre a pega correta:

Ficar observando se a neném está pegando o bico certinho, para não machucar, elas assim deram mais ênfase nisso, ficar observando sempre isso, se a linguinha está pegando direitinho para não ferir o bico do peito. (P3)

Boquinha bem colada bem para fora e o bico bem para dentro e os olhos no olho da mãe. (P4)

É prestar atenção na sucção da criança, vê se ela está sugando bem. (P5)

A terceira orientação relatada pelas puérperas foi quanto à alternância das mamas a cada mamada:

Fazer o revezamento das mamas para não ter problema, nem no tamanho e também para ter melhor produçâo. (P3) Mamou em um peito passa para o outro, na próxima mamada ou se a criança quiser continuar mamando. (P5) 
A quarta orientação foi o posicionamento adequado para amamentar:

Orientaram de barriga para a frente para minha né. Rostinho bem colado com a mama. (P2)

Elas me explicaram junto ao corpo, o nariz na altura do bico, o queixo quer dizer na altura do bico. (P3)

Tem que ficar com a barriguinha colada aqui na mäe, a mãozinha de baixo, não pode ficar pressionada assim, tem que ficar atrás como se tivesse me abraçando. (P12)

A quinta orientação citada pelas puérperas foi a duração da mamada:

De 20 a 30 minutos mais ou menos né, para ficar com o peito na boca. (P2)

No começo foi 20 minutos, aí depois já estava o tempo que queria. (P3)

Duração de 40 minutos assim, ontem elas falaram para eu deixar mamar à vontade né. (P4)

\section{Contradições nas abordagens educacionais realizadas pelos enfermeiros}

Elas orientam direitinho, e orientam as mesmas coisas, só que falam diferente ai confunde. (P15)

As enfermeiras falam muito, eu entendo, mas ai vem outra e fala de outra maneira, ai não sei direito se as orientaçōes são iguais. (P2)

Orientação não falta, mas falta uma padronização entre elas, cada uma fala de um jeito. (P7)

\section{Discussão}

Esta investigação almejou contribuir para a estruturação de um arcabouço teórico embasado cientificamente para promoção do processo de orientação quanto à amamentação eficaz no período do puerpério, ainda em ambiente hospitalar, na expectativa de construção de protocolos e de treinamentos que favoreçam tal prática e alinhe a abordagem realizada pelos profissionais para a educação realizada beira-leito. O método qualitativo foi escolhido por possibilitar a apreensão profunda da percepçáo e dos sentimentos dos participantes envolvidos, buscando compreender como se configura o quadro de orientaçóes para amamentação, na perspectiva do enfermeiro e da puérpera, para análise e adequação deste contexto, diante da comparação de ambos os cenários. Considerou-se como limitação a incipiência literária específica sobre as orientaçôes abordadas. Nota-se que as orientaçôes relatadas pelos enfermeiros e percebidas pelas puérperas corroboram inicialmente no que tange à necessidade de educação para facilitação desta prática.

A primeira orientação destacada pelos profissionais e corroborada pelas puérperas foi o tempo de mamada ideal para o bebê. Os profissionais participantes orientaram que cada mamada deve ter a duração de 20 a 30 minutos. Segundo o manual do Ministério da Saúde, ${ }^{3}$ o tempo de permanência na mama em cada mamada náo deve ser fixado, pois o tempo necessário para esvaziar uma mama difere para cada mulher e bebê, dependendo da fome da criança, do intervalo transcorrido desde a última mamada e do volume de leite armazenado na mama, entre outros.

Estudo metodológico realizado com 17 puérperas em uma maternidade referência em Fortaleza (CE) identificou que parte dessa população não respeita a livre demanda da amamentação, ou seja, a permanência do bebê na mama pelo tempo que este desejar, fato que repercutiu no ganho de peso da criança e na construção do mito de que o leite materno é fraco. Fez-se necessário enfatizar que a criança deve permanecer em uma mesma mama até que esteja saciada ${ }^{13}$.

Enfermeiros e puérperas estipularam a duração da mamada nesta pesquisa, em seus apontamentos. Já o Ministério da Saúde esclarece que a duração ou o horário para o bebê mamar náo sejam estipulados, estimulando a livre demanda. Evidencia-se a necessidade de adequar tal orientação ${ }^{3}$.

A pega correta foi destacada como orientação por enfermeiros e pelas máes. Para ambos, a pega correta se faz eficaz quando os lábios estão virados para fora, abocanhando sempre ao máximo a região da aréola, e não somente o bico da mama. Estudo realizado com gestantes em um serviço de assistência pré-natal de uma unidade de Saúde da Família evidenciou que, para o bebê fazer uma pega na mama corretamente, ele deve ter uma abertura oral ampla, abocanhando tanto mamilo quanto parte da aréola, garantindo a formação de vácuo entre boca e mama, o que corrobora as orientaçóes do Ministério da Saúde ${ }^{3,14}$.

O posicionamento correto para amamentação foi apontado como terceira orientaçáo realizada pelos enfermeiros e percebida pelas puérperas. Os profissionais indicaram que a mãe deveria estar em uma posição confortável, sentada com o braço apoiado e o abdômen do bebê próximo ao seu, a cabeça da criança alinhada com o cotovelo e de frente para a aréola da mama. O manual refere que a cabeça e o tronco do bebê devem estar alinhados (pescoço não torcido), com o rosto do bebê de frente para a mama, o nariz na altura do mamilo, e o corpo do bebê próximo ao da mãe e bem apoiado 3 . O posicionamento correto, durante o ato do aleitamento materno, é o bebê de frente para a nutriz, barriga com 
barriga $^{15}$. Assim, as orientaçóes realizadas pelos enfermeiros nesta pesquisa condizem com as da literatura.

A quarta orientação foi sobre a necessidade de alternar a mama a cada mamada. As orientaçóes realizadas apontaram a necessidade de trocar a mama a cada mamada, ou seja, intercalar as mamas. É importante orientar a genitora sobre alternância das mamas e seu esvaziamento completo durante a amamentaçáo, indicando que, caso a mama não seja esvaziada na primeira mamada, deve ocorrer o retorno para a mesma mama até esvaziá-la, garantindo que o bebê mame o leite do início e do final da mamada, para obter todos os nutrientes ${ }^{16}$. O Ministério da Saúde orienta que o bebê esvazie toda a mama e somente entấo a mãe poderá oferecer a outra mama. ${ }^{3}$ Apesar de as puérperas perceberem a necessidade de alternar a mama a cada mamada, as falas das mães não evidenciaram a correta justificativa para tal, fato possivelmente explicado pela dificuldade de alinhamento na explicação realizada pelos profissionais enfermeiros beira-leito.

A troca de mama, entre uma mamada e outra, é importante para sucção total de todos os nutrientes necessários até o fim da mamada. Caso o bebê mame apenas parte do leite, ele náo usufrui de todos os componentes essenciais para o sistema imunológico e crescimento saudável ${ }^{3}$.

A quinta orientação realizada pelo profissional enfermeiro e apontada também pelas puérperas foi sobre o tempo de intervalo entre cada mamada. Estudo de caráter transversal destacou que a criança deve ser amamentada sem restrição de horários e de tempo de permanência na mama, ou seja, num esquema de livre demanda. Tal orientação é confirmada pelo Ministério da Saúde ${ }^{3,17}$.

Cabe salientar as lacunas existentes no processo de orientação para amamentação destacadas na percepção dos enfermeiros e pelas pacientes participantes neste contexto.

Os profissionais indicaram que as mães possuíam conhecimento insuficiente sobre amamentação, o que as torna inseguras em relação ao ato de amamentar. As orientaçóes sobre aleitamento materno transmitidas pelos profissionais de saúde ampliam os conhecimentos das mulheres e de suas famílias, tornando-as capazes de atingir o sucesso de uma prática correta ${ }^{18}$. $\mathrm{A}$ informaçáo à puérpera constitui o elemento mais relevante para evitar problemas ou dificuldades durante o processo de amamentar. Assim, tornam-se necessários os aprofundamentos teórico e prático dos profissionais de saúde, além de açóes e políticas que estimulem o manejo clínico da amamentação ${ }^{19}$.

A lacuna de conhecimento sobre amamentação percebida nas puérperas participantes desta pesquisa ajudou a detectar a segunda necessidade: a dificuldade do enfermeiro em apropriar-se de sua função de educador. Segundo a lei 7.498, que rege a profissáo da enfermagem, cabe ao profissional enfermeiro, como integrante da equipe de saúde, a educação visando à melhora de saúde da população ${ }^{20}$. Assim, é inerente ao enfermeiro o processo de educação do paciente, e a delegação desta função deve ser tratada com cuidado e rigor. Para que a equipe técnica participe de processos educativos, propiciando o trabalho integrado e conjunto, é preciso repensar a prática de treinamento e a padronização de linguagem, alinhando as medidas ensinadas para as pacientes ${ }^{21}$.

O terceiro apontamento citado pelos enfermeiros foi a necessidade de fortalecer o vínculo entre atenção primária e atenção terciária na saúde. Os profissionais enfermeiros questionam que a mãe deveria receber orientaçóes sobre amamentação no pré-natal, ou seja, na atenção primária, havendo, assim, o fortalecimento das redes de atenção. Como integrantes de um sistema, as organizaçóes de saúde formam uma complexa rede, cuja constituição inclui estrutura logística e modelos assistenciais e de gestão. Tais sistemas definem o contexto dos serviços de saúde, que podem ser caracterizados sob diferentes formas com relação à integração em rede. A reestruturação do Sistema Único de Saúde (SUS), na perspectiva de rede de atenção, é uma estratégia de superação do modo fragmentado de operar a assistência e a gestão em saúde, significando o pensar em saúde nas diferentes esferas: primária, secundária e terciária. A prática da amamentação deve se iniciar na promoção da atenção primária, com o processo de educação estimulado ainda no pré-natal, e ter continuidade no ambiente hospitalar, após o nascimento do bebê, para detecção de dificuldades que reduzem a adesão das puérperas ${ }^{21}$.

Em relação às contradiçôes nas abordagens educacionais realizadas percebidas pelas puérperas, notou-se que, apesar de as orientações serem realizadas, há ausência de protocolos que uniformizem e qualifiquem a maneira de realizar a educação beira-leito, de forma clara, didática e apropriada para as pacientes.

É importante salientar que a falta de padronização da linguagem referente às ações dos enfermeiros é uma grande dificuldade encontrada na prática diária, que influencia negativamente a qualidade da assistência prestada e a percepção do cuidado pelo paciente, apontando necessidade de adoção de protocolos que estabeleçam e organizem as ações de cuidado.

Protocolos em saúde são considerados tecnologias que funcionam como ferramentas importantes para o enfrentamento de diversos problemas na assistência e na gestáo dos serviços ${ }^{22}$. Eles devem ser guiados por diretrizes de natureza técnica, organizacional e política, têm 
como fundamentação estudos validados pelos pressupostos das evidências científicas, sendo elaborados por profissionais experientes e especialistas em uma área, e servem para orientar fluxos, condutas e procedimentos clínicos de trabalhadores dos serviços de saúde ${ }^{23}$.

Sáo apontados como organizadores do serviço de enfermagem e produtos tecnológicos que proporcionam a sistematização, a facilidade no processo de trabalho, a orientaçáo e, em especial, a humanização do cuidado, com melhoria da qualidade de vida dos usuários ${ }^{24}$.

Os profissionais enfermeiros devem ter embasamento científico para saber cuidar e ensinar. Buscar conhecimento é um processo de construção e, nesse sentido, é importante refletir sobre seu processo de formação, pois a busca por informações possibilita atingir um processo de amamentação eficaz, que auxilie as puérperas na adesão da prática, e a articulação de saberes científicos com a prática educativa embasada em protocolos e treinamentos pode proporcionar a excelência do cuidado ${ }^{25}$.

\section{Conclusão}

Apesar de as orientaçóes realizadas pela equipe de profissionais enfermeiros corroborarem as informaçóes percebidas beira-leito pelas puérperas participantes, cabe ressaltar neste contexto que as contradiçóes identificadas nas abordagens educacionais realizadas pelos enfermeiros reforçam significativamente a importância da adoção de protocolos que organizem e especifiquem esta prática na busca de um alinhamento da assistência prestada para a adesão e qualidade da amamentação.

Este estudo apresentou como limitaçấo o número de participantes incluídos, pois considerou especificamente o setor de maternidade e os profissionais pertencentes a este local. Percebe-se também uma incipiência em relação a estudos nacionais e internacionais que abordem a desarticulação nos processos de educação e orientação à beira-leito do enfermeiro, o que torna imprescindível o aprofundamento científico neste âmbito.

Evidencia-se, enfim, a necessidade da apropriação da competência de educar pelo enfermeiro e da aquisição de documentos e protocolos baseados em referenciais científicos confiáveis, que eliminem as contradiçóes na abordagem das orientaçóes necessárias para a excelência do processo de amamentação.

\section{Referências}

1. Amitay EL, Keinan-Boker L. Breastfeeding and childhood leukemia incidence: a meta-analysis and systematic review. JAMA Pediatr. 2015;169(6):e151025. Erratum in: JAMA
Pediatr. 2015;169(8):791; JAMA Pediatr. 2015;169(8):791; JAMA Pediatr. 2015;169(11):1072.

2. United Nations Children's Fund (Unicef). Breastfeeding on the worldwide agenda. Findings from a landscape analysis on political commitment for programmes to protect, promote and support breastfeeding [Internet]. New York: Unicef; 2013 [citado em 2017 jun 5]. Disponível em: https://goo.gl/oBdQmy.

3. Brasil. Ministério da Saúde. Cadernos de atenção básica: saúde da criança. Aleitamento materno e alimentaçáo complementar [Internet]. Brasília, DF: Ministério da Saúde; 2015 [citado em 2017 jun 5]. Disponível em: https://goo. $\mathrm{gl} / \mathrm{Me} 8 \mathrm{TbV}$.

4. Brasil. Ministério da Saúde. Portal da Saúde. Brasil é referência mundial em amamentação [Internet]. Brasília, DF: Ministério da Saúde; 2016 [citado em 2017 maio 29]. Disponível em: https://goo.gl/Kv8457.

5. Almeida JA, Luz SA, Ued FV. Apoio ao aleitamento materno pelos profissionais de saúde: revisão integrativa da literatura. Rev Paul Pediatr [Internet]. 2015 [citado em 2017 maio 29];33(3):355-62. Disponível em: https://goo. $\mathrm{gl} / \mathrm{q} 5 \operatorname{Kog} 5$.

6. Visintin AB, Primo CC, Amorim MHC, Leite FMC. Avaliação do conhecimento de puérperas acerca da amamentação. Enferm Foco [Internet]. 2015 [citado em 2017 jun 5]; 6(1/4): 12-6. Disponível em: https://goo.gl/ QHrYor.

7. Duarte EF, Santos CSE, Couto MGC, Andrade VLFS, Matos RCP, Santos EI. Estratégias utilizadas por enfermeiros na promoçáo do aleitamento materno no puerpério imediato. Rev Cuid [Internet]. 2013 [citado em 2017 jun 5]; 4(1). Disponível em: https://goo.gl/MgUwQK.

8. Silva NM, Waterkemper R, Silva EF, Cordova FP, Bonilha ALL. Conhecimento de puérperas sobre amamentação exclusiva. Rev Bras Enferm [Internet]. 2014 [citado em 2017 jun 5]; 67(2):290-5. Disponível em: https://goo.gl/ FWTvnW.

9. Marinho MS, Andrade EN, Abrão ACFV. A atuação do(a) enfermeiro(a) na promoção, inventivo e apoio ao aleitamento materno. Rev Rec. 2015;4(2):189-198.

10. Cunha EC, Siqueira HCH. Aleitamento materno: contribuiçôes da enfermagem. Ensaios Cienc, Cienc Biol Agrar Saúde [Internet]. 2016 [citado em 2017 jun. 5];20(2):8692. Disponível em: https://goo.gl/qRWg8m.

11. Cavalcante RB, Calixto P, Pinheiro MMK. Content analysis: general considerations, relations with the research question, the possibilities and limitations of the method. Inf \& Soc: Est [Internet]. 2014 [citado em 2017 jun 5];24(1):138. Disponível em: https://goo.gl/u4sX27.

12. Costa PB, Chagas ACMA, Joventino ES, Dodt RCM, Oría MOB, Ximenes LB. Development and validation of educational manual for the promotion of breastfeeding. Rev Rene. 2013;14(6):1160-7. 
13. Cordeiro EL, Santana I, Coelho M, Souza RM, Cassilha AP. Preparo das gestantes na técnica de amamentação em uma unidade de saúde da família no município de Olinda PE. Revista Universo [Internet]. 2013 [citado em 2017 jun 5];7:1-18. Disponível em: https://goo.gl/bawByQ.

14. Azevedo ARR, Alves VH, Souza RMP, Rodrigues DP, Branco MBLR, Cruz AFN. Clinical management of breastfeeding: knowledge of nurses. Esc Anna Nery [Internet]. 2015 [citado em 2017 maio 29];19(3):439-45. Disponível em: https://goo.gl/7SnSef.

15. Soares JPO, Novaes LFG, Araújo CMT, Vieira ACC. Amamentação natural de recém-nascidos pré-termo sob a ótica materna: uma revisão integrativa. Rev CEFAC [Internet]. 2016 [citado em 2017 maio 29];18(1):232-41. Disponível em: https://goo.gl/xcg9aN.

16. Franco SC, Silva ACA, Tamesawa CS, Ferreira GM, Feijó JMY, Macaris T, et al. Escolaridade e conhecimento sobre duração recomendada para o aleitamento materno exclusivo entre gestantes na estratégia de saúde da família. Arq Catarin Med [Internet]. 2015 [citado em 2017 jun 5];44(3):66-77. Disponível em: https://goo.gl/FDFYVn.

17. Silva NM, Warterkemper R, Silva EF, Cordova FP, Bonilha ALL. Conhecimento de puérperas sobre amamentação exclusiva. Rev Bras Enferm. 2014;67(2):290-5.

18. Vargas GS, Alves VH, Rodrigues DP, Branco MBLR, Souza RMP, Guerra JVV. Atuação dos profissionais de saúde da estratégia saúde da família: promoção da prática do aleitamento materno. Rev Baiana Enferm [Internet]. 2016 [citado em 2017 maio 29];30(2):1-9. Disponível em: https:// goo.gl/tHwChw.
19. Brasil. Presidência da República. Subchefia para Assuntos Jurídicos. Lei no 7.498, de 25 de junho de 1986. Dispóe sobre a regulamentação do exercício da enfermagem, e dá outras providências [Internet]. Brasília, DF; 1986 [citado em 2017 maio 29]. Disponível em: https:/goo.gl/o1dyu9.

20. Oliveira MR, Leonel AR, Montezeli JH, Gastaldi AB, Martins EA, Caveião C. Conception of undergraduate nursing students on the practice of health education on first aid. Rev Rene. 2015;16(2):150-8.

21. Erdmann AL, Andrade SR, Mello ALSF, Drago LC. A atenção secundária em saúde: melhores práticas na rede de serviços. Rev Latino-Am Enfermagem [Internet]. 2013 [citado em 2017 maio 29];21(Esp):[8 telas]. Disponível em: https://goo.gl/elogAq.

22. Werneck MAF, Faria HP, Campos KFC. Protocolo de cuidados à saúde e de organizaçáo do serviço. Belo Horizonte: Nescon/UFMG; Coopmed, 2009.

23. Gubert FA, Santos DAS, Pinheiro MTM, Brito LLMS, Pinheiro SRCS, Martins MC. Protocolo de Enfermagem para consulta de puericultura. Rev Rene. 2015;16(1):81-9.

24. Alves KYA, Salvador PTCO, Santos VEP, Martins CCF, Costa TD. Cuidar-curar transpessoal e os protocolos de enfermagem: "cuidado com a vida". Rev Enferm UFSM [Internet]. 2014 [citado em 2017 jun 5];4(4):858-64. Disponível em https://goo.gl/ZSaBH7.

25. Moura LK, Lima CH, Sousa FD, Honorato DZ, Neta AS, Costa KR. The professional nurse as educator: a look to primary health care and the NASF. Revista Interdisciplinar. 2015;8(1):211-9.

\section{Como citar este artigo:}

Mendes-Rodrigues C, Costa KES, Antunes AV, Gomes FA, Rezende G Jr, Silva DV. Carga de trabalho e dimensionamento de pessoal de enfermagem em unidades de terapia intensiva. Rev. Aten. Saúde. 2017;15(53):13-20. 